\title{
KOMUNIKASI DALAM PENERAPAN SISTEM JAJAR LEGOWO DI DESA MURNI JAYA KECAMATAN TUMIJAJAR KABUPATEN TULANG BAWANG BARAT
}

\section{COMMUNICATION IN THE IMPLEMENTATION OF JAJAR LEGOWO SYSTEM IN MURNI JAYA, TUMIJAJAR SUBDISTRICT, TULANG BAWANG BARAT DISTRICT}

\author{
Erika Dwi Alviana, Tri Pujiana*, Dwi Arianti, Helvi Yanfika \\ Magister Penyuluhan dan Komunikasi Pertanian, Fakultas Pertanian, \\ Universitas Lampung Bandar Lampung 35141 \\ *E-mail: tripujiana.unila@gmail.com \\ (Diterima 21-02-2019; Disetujui 15 Juli 2019)
}

\begin{abstract}
ABSTRAK
Tujuan dari penelitian ini adalah untuk mengetahui proses komunikasi antara penyuluh dengan petani dalam penerapan sistem Jajar Legowo di Desa Murni Jaya Kecamatan Tumujajar Kabupaten Tulang Bawang Barat. Penentuan lokasi penelitian dilakukan secara sengaja (purposive sampling). Pengumpulan data dilakukan pada bulan November 2018. Jenis penelitian ini merupakan penelitian kualitatif. Teknik pengumpulan data dengan melakukan observasi langsung ke tempat penelitian, wawancara depth interview dengan pengurus kelompok tani dan penyuluh, serta studi kepustakaan. Metode analisis data adalah dengan deskriptif kualitatif. Fokus pada penelitian ini adalah kendala komunikasi antara penyuluh dan Gapoktan Mekar Jaya Sri dalam penerapan Sistem Tanam Jajar Legowo dan solusi untuk menangani masalah tersebut. Hasil penelitian menunjukkan bahwa komunikasi yang dilakukan penyuluh sudah cukup baik, hal ini karena penyuluh melakukan pertemuan dengan anggota kelompok tani sebulan sekali, melakukan anjang sana dan anjang karya. Sedangkan petani yang belum mau menerapkan Sistem Tanam Jajar Legowo disebabkan oleh sifat inovasi yang rumit dan pengeluaran biaya untuk menerapkan inovasi tersebut lebih besar daripada menggunakan sistem tanam sebelumnya, sehingga masih ada keraguan petani untuk menerapkan inovasi tersebut. Upaya yang dilakukan untuk mengatasi kendala tersebut, yaitu perlu adanya perbaikan pada persepsi petani terhadap Sistem Tanam Jajar Legowo, penyuluh perlu meningkatkan intensitas pendampingan kepada petani, dan juga perlu melakukan pengontrolan dan evaluasi terhadap usahatani padi yang dilakukan oleh petani padi di Desa Murni Jaya.
\end{abstract}

Kata kunci: inovasi, komunikasi, sistem Jajar Legowo

\begin{abstract}
The purpose of this study was to find out the communication process between extension agents and farmers in implementing the Jajar Legowo system in Murni Jaya, Tumujajar District, Tulang Bawang Barat District. The location of the study was determined purposively. Data collection was conducted in November 2018. This type of research is qualitative research. Data collection techniques by conducting direct observations to the research site, deep interview interviews with the management of farmer and extension groups, and literature studies. The method of data analysis is descriptive qualitative. The focus of this research is the obstacle of communication between Mekar Jaya Jaya extension agents and Gapoktan in the implementation of the Jajar Legowo Planting System and the solution to deal with the problem. The results of the study showed that the communication carried out by the instructor was quite good, this was because the instructor had meetings with members of the farmer group once a month, carried out the program and continued the work. Whereas farmers who did not want to implement the Jajar Legowo Planting System were caused by the complex nature of the innovation and the cost of implementing the innovation was greater than using the previous planting system, so there were still doubts by farmers to implement the innovation. Efforts are being made to overcome these obstacles, namely the need to improve farmers' perceptions of the Jajar Legowo Planting System, extension workers
\end{abstract}




\section{KOMUNIKASI DALAM PENERAPAN SISTEM JAJAR LEGOWO DI DESA MURNI JAYA \\ KECAMATAN TUMIJAJAR KABUPATEN TULANG BAWANG BARAT \\ Erika Dwi Alviana, Tri Pujiana, Dwi Arianti, Helvi Yanfika}

need to increase the intensity of assistance to farmers, and also need to control and evaluate rice farming carried out by rice farmers in Murni Jaya Village.

Keywords: communication, innovation, Jajar Legowo system

\section{PENDAHULUAN}

Pangan merupakan kebutuhan dasar bagi manusia yang harus dipenuhi setiap saat. Pangan di Indonesia sering diidentikkan dengan padi karena jenis pangan ini merupakan makanan pokok bagi masyarakat Indonesia. Ketersediaan pangan yang lebih kecil dibandingkan kebutuhannya dapat menciptakan ketidakstabilan ekonomi (Bulog, 2016). Abdulrachman dan Jamal (2007) mengemukakan bahwa pada kondisi terkontrol melalui penelitian, teknik intensifikasi pertanian mampu meningkatkan produktivitas padi sekitar 38\%. Salah satu inovasi intensifikasi padi adalah penggunaan jarak tanam (Deptan, 2009). Penerapan sistem tanam yang benar dan baik melalui pengaturan jarak tanam dikenal dengan Sistem Tanam Jajar Legowo, sistem tanam ini lebih direkomendasikan untuk digunakan karena sistem Jajar Legowo memiliki lebih banyak keuntungan jika dibandingkan dengan sistem tanam yang lain (Ikhwani et al, 2013).

Hasil penelitian di Sukamandi Kabupaten Subang Provinsi Jawa Barat selama dua musim menunjukkan cara tanam Jajar Legowo 2:1 meningkatkan hasil padi sawah 1,9-29\% pada musim kemarau 2007 dan 2,4-11,3\% pada musim kemarau 2008 (Laila dkk, 2012). Inovasi Sistem Tanam Jajar Legowo yang memiliki banyak kelebihan ini perlu mendapatkan respon positif dari petani agar mereka mau menerapkan Sistem Tanam Jajar Legowo supaya produktivitas padi dan pendapatan mereka dapat meningkat.

Sistem Jajar Legowo merupakan salah satu inovasi dalam bidang pertanian. Penyebaran inovasi ini membutuhkan peran serta penyuluh untuk mengomunikasikan program kepada masyarakat petani (Pratama, 2016). Komunikasi merupakan penyampaian informasi dari komunikator kepada komunikan. Proses pengiriman pesan dalam komunikasi membutuhkan keterampilan dalam memaknai pesan baik oleh komunikator maupun komunikan. Dalam menyebarluaskan inovasi Jajar Legowo, penyuluh pertanian bertindak sebagai komunikator sedangkan petani padi bertindak sebagai komunikan.

Penyuluhan sebagai upaya yang efektif dalam mendorong pembangunan pertanian pada kondisi keterbatasan petani dalam mengakses pengetahuan dan informasi. Penyuluh pertanian juga 
diharapkan memperkenalkan pertanian berkelanjutan yang menuntut keterampilan-keterampilan baru. Banyak program pertanian yang telah diluncurkan oleh pemerintah, mulai dengan pendekatan top down sampai dengan bottom up. Salah satu program yang diturunkan adalah sistem tanam Jajar Legowo yang mulai dikenalkan kepada petani sejak tahun 2007 (Abdulrachman et al, 2013).

\section{Desa Murni Jaya Kecamatan} Tumijajar merupakan desa yang telah menerima sosialisasi sistem tanam Jajar Legowo sejak tahun 2015. Penerapan suatu inovasi diawali dengan komunikasi dari penyuluh pertanian. Penyuluh memberikan edukasi tentang inovasi tersebut melalui pertemuan Gapoktan dan praktik langsung di lapang. Hal ini dilakukan agar petani padi tidak hanya diperdengarkan dan diperlihatkan saja, tetapi diragakan dan diberi kesempatan untuk melakukannya.

Penyuluhan sebagai upaya pendidikan non formal dimaksudkan untuk mengajak orang secara sadar dan mau menerapkan ide-ide baru. Komunikasi dan metode penyuluhan yang dipilih merupakan hal penting dalam suatu kegiatan penyuluhan. Apabila komunikasi yang dilakukan oleh penyuluh di Desa Murni Jaya tepat maka inovasi tentang sistem tanam Jajar Legowo tersampaikan dengan baik ke petani dan petani menerapkan sistem tersebut di usahatani mereka. Tujuan dari penelitian ini adalah mengetahui bagaimana komunikasi yang dilakukan oleh penyuluh tentang peneran sistem tanam Jajar Legowo di Murni Jaya Kecamatan Tumijajar Kabupaten Tulang Bawang Barat.

\section{METODE PENELITIAN}

Jenis penelitian ini merupakan penelitian kualitatif. Menurut Nugrahani (2014), tujuan dari penelitian kualitatif adalah untuk memahami suatu konteks dengan mendeskripsikan secara rinci mengenai kondisi tentang apa yang sebenarnya terjadi di lapangan. Melalui penelitian kualitatif dapat diperoleh pemahaman tentang kenyataan melalui proses berpikir induktif. Motode berpikir induktif adalah metode yang digunakan dalam berpikir dengan bertolak dari hal khusus untuk mendapatkan kesimpulan yang bersifat umum.

Penelitian dilakukan di Desa Murni Jaya Kecamatan Tumujajar Kabupaten Tulang Bawang Barat. Petani di desa ini melakukan usahatani padi sawah. Penentuan lokasi penelitian dilakukan secara sengaja. Pengumpulan data pada bulan November 2018.

Penelitian ini meneliti satu gapoktan yang ada di Desa Murni Jaya. Subjek 
penelitian ini adalah Gapoktan Mekar Jaya yang mengikuti program sistem tanam Jajar Legowo. Informan dari penelitian ini yaitu ketua gapoktan dan penyuluh yang ada di Desa Murni Jaya. Informan penelitian ditentukan secara purposive sampling yang bertitik tolak pada penilaian pribadi peneliti berdasarkan pada kriteria-kriteria yang telah dirumuskan terlebih dahulu oleh peneliti (Sugiatro dalam Firmansyah, 2015). Informan diminta untuk memberikan respon terhadap pertanyaan yang diberikan baik langsung atau tidak langsung, secara lisan atau tertulis maupun berupa perbuatan yang diajukan oleh peneliti (Subliyanto, 2010).

Teknik pengumpulan data dalam penelitian ini adalah dengan melakukan observasi, wawancara dan dokumentasi. Observasi langsung ke tempat penelitian dengan melakukan pengamatan, pencatatan secara sistematik kejadian-kejadian, perilaku dan objek yang dilihat serta hal lain yang mendukung penelitian. Wawancara dilakukan kepada informan yang terbatas menggunakan instrumen berupa pedoman wawancara. Informan adalah orang yang dianggap banyak mengetahui tentang penyuluhan pertanian (Ekasari et al, 2015) di Desa Murni Jaya.

Fokus penelitian ini adalah komunikasi antara penyuluh dan Gapoktan
Mekar Jaya Sri dalam penerapan sistem tanam Jajar Legowo, kendala dan solusi untuk menangani masalah yang terjadi. Metode analisis data yang digunakan dalam penelitian ini adalah dengan deskriptif kualitatif. Analisis data dilakukan untuk memberikan makna, menafsirkan atau mentransformasikan data ke dalam narasi sehingga dapat ditarik kesimpulan. Analisis data kualitatif dimulai dari analisis berbagai data yang dikumpulkan dari lapangan. Kemudian data dikalsifikasikan menjadi kategori tertentu dengan mempertimbangkan keabsahan data, kemudian dilakukan pemaknaan terhadap data yang berlandaskan pada teori untuk menjelaskan dan berargumentasi.

\section{HASIL DAN PEMBAHASAN}

Desa Murni Jaya adalah salah satu desa yang terletak di Kecamatan Tumijajar Kabupaten Tulang Bawang Barat. Desa Murni Jaya memiliki jumlah penduduk pria sebanyak 1.898 jiwa dan penduduk wanita sebanyak 2.135 wanita. Di Desa Murni Jaya terdapat satu gapoktan yang bernama Gapoktan Mekar Jaya. Gapoktan Mekar Jaya terdiri atas 22 kelompok tani, dengan jumlah anggotanya sebanyak 517 petani. Sebagian besar mata pencaharian masyarakat Murni Jaya adalah bertani. Selain itu, pekerjaan yang ditekuni masyarakat Murni Jaya adalah 
pedagang, pegawai negeri, swasta, dan lain sebagainya.

\section{Komunikasi Penyuluh tentang Sistem Tanam Jajar Legowo di Desa Murni Jaya}

Pesan informasi yang disampaikan oleh penyuluh pertanian di Desa Murni Jaya merupakan bagian komunikator dalam menyampaikan informasi kepada petani di lapangan. Proses penyampaian informasi akan berjalan efektif jika jumlah tenaga penyuluh tersedia secara memadai sehingga seluruh isi pesan dapat diterima oleh kelompok sasaran komunikasi. Selain itu, dalam proses menyampaikan pesan informasi, tenaga penyuluh pertanian juga harus memiliki kepribadian yang baik dalam menjalankan tugasnya agar keberadaannya dapat diterima oleh petani.

Penyuluhan pertanian mengupayakan perubahan perilaku petani dan keluarganya agar mampu memecahkan masalahnya sendiri dalam kegiatan usahataninya. Penyuluhan berperan dalam peningkatan pengetahuan petani tentang informasi pertanian yang baru. Penyuluh dalam hal ini berfungsi sebagai penyebarluasan informasi, memberikan penerangan dan penjelasan kepada petani.

Perkembangan petani di Desa Murni Jaya saat ini sudah mulai menunjukkan perbaikan setelah diberikan penyuluhan dari Badan Penyuluhan Pertanian di lapangan.
Menurut informan, peranan komunikasi penyuluhan yang dilakukan oleh penyuluh antara lain penggalian informasi mengenai kebutuhan petani selama satu tahun. Penggalian informasi melalui pertemuan langsung di lapangan dengan petani binaannya.

Materi penyuluhan dibuat dalam rangka peningkatan produksi dan menyesuaikan dengan isu global sebagai upaya menyiapkan petani dalam mengatasi persoalan iklim global. Materi penyuluhan juga dibuat berorientasi pada teknik bertani yang ramah lingkungan seperti penggunaan pupuk organik. Pupuk organik perlu diaplikasikan untuk mengurangi penggunaan pupuk kimia secara berlebihan yang berdampak buruk pada sistem pertanian jangka panjang.

Informasi lain mengenai teknologi baru yang disampaikan dalam penyuluhan adalah sistem tanam dengan Jajar Legowo. Sistem tanam Jajar Legowo dikembangkan dari sistem tanam tegel yang telah berkernbang di masyarakat. Legowo berasal dari bahasa Jawa yang artinya lego (lega/luas) dan dowo (memanjang). Sistem Tanam Jajar Legowo merupakan sistem tanam pindah dengan membuat lorong kosong memanjang sejajar dengan barisan tanaman padi di antara 2-4 barisan. 


\section{KOMUNIKASI DALAM PENERAPAN SISTEM JAJAR LEGOWO DI DESA MURNI JAYA \\ KECAMATAN TUMIJAJAR KABUPATEN TULANG BAWANG BARAT \\ Erika Dwi Alviana, Tri Pujiana, Dwi Arianti, Helvi Yanfika}

Jarak tanam dalam barisan Jajar Legowo menjadi setengah jarak tanam antar baris, sehingga terjadi pemadatan rumpun padi di dalam barisan dan memperlebar jarak antar barisan. Sistem Tanam Jajar Legowo menjadikan dua baris semua rumpun padi berada di barisan pinggir dari pertanaman, akibatnya semua rumpun padi tersebut memperoleh manfaat dari pengaruh (border effect) (Suriapermana et al, 1994).

Menurut Sembiring (2001), Sistem Tanam Jajar Legowo merupakan salah satu komponen pengelolaan tanaman terpadu pada padi sawah yang apabila dibandingkan dengan sistem tanam lainnya memiliki keuntungan sebagai berikut: (1) terdapat ruang terbuka yang lebih lebar di antara dua kelompok barisan tanaman yang akan memperbanyak cahaya matahari masuk ke setiap rumpun tanaman padi sehingga meningkatkan aktivitas fotosintesis yang berdampak pada peningkatan produktivitas tanaman; sistem tanaman berbaris ini memberi kemudahan petani dalam pengelolaan usahataninya seperti meningkatkan jumlah tanaman pada kedua bagian pinggir untuk setiap set legowo, sehingga berpeluang untuk meningkatkan produktivitas tanaman akibat peningkatan populasi; (3) sistem tanaman berbaris ini juga berpeluang bagi pengembangan sistem mina padi atau parlebek; (4) meningkatkan produktivitas padi hingga mencapai 10-15 persen.

Desa Murni Jaya merupakan salah satu desa yang memiliki produktivitas padi yang paling rendah di Kecamatan Tumijajar, produktivitas di desa ini hanya mencapai 5,0 ton/ha sedangkan desa lain dapat mencapai 5,5-5,75 ton per hektar. Hal ini disebabkan oleh penerapan Sistem Tanam Jajar Legowo yang masih rendah (Alviana, 2018).

Rendahnya penerapan Sistem Tanam Jajar Legowo merupakan permasalahan yang terjadi di Desa Murni Jaya sejak awal pengenalan Sistem Tanam Jajar Legowo. Menurut penyuluh dan ketua gapoktan, kegiatan sosialisasi telah dilakukan dengan cara praktik penanaman dengan menggunakan Sistem Tanam Jajar Legowo di beberapa sekatar sawah yang disaksikan dan di ikuti oleh petani daerah tersebut. Hasil dari praktik penerapan Sistem Tanam Jajar Legowo tersebut tergolong berhasil, terjadi peningkatan produktivitas padi sekitar 1-1,5 ton/ha.

Namun, petani masih ada yang salah menggunakan jarak tanam Sistem Tanam Jajar Legowo, jarak tanam yang seharusnya adalah $(12,5 \mathrm{~cm} \times 12,5 \mathrm{~cm}) \times 50 \mathrm{~cm}$ menjadi $(20 \mathrm{~cm} \times 20 \mathrm{~cm}) \times 50 \mathrm{~cm}$ atau malah tetap menggunakan jarak tanam sebelumnya yaitu $25 \mathrm{~cm} \times 25 \mathrm{~cm} \times 25 \mathrm{~cm}$. Kesalahan pemahaman petani tentang 
jarak tanam ini mengakibatkan produktivitas yang lebih rendah daripada desa lain di Kecamatan Tumijajar.

Menurut ketua gapoktan, selain kurangnya sosialisasi kembali tentang Sistem Tanam Jajar Legowo, rumitnya sifat inovasi Sistem Tanam Jajar Legowo juga menjadi alasan petani masih salah menggunakan Sistem Tanam Jajar Legowo pada usahatani mereka.

Penyuluh melakukan pertemuan sebulan sekali dengan anggota kelompok tani, melayani anjang sana dan anjang karya. Penyuluh mendatangi rumah dan dan lokasi usahatani guna memberikan pengertian dan memecahkan masalah seputar usahatani padi. Salah satu yang menjadi tekanan penyuluh adalah penggunaan Sistem Tanam Jajar Legowo. Penyuluh melakukan penyuluhan Sistem Tanam Jajar Legowo sesuai dengan petunjuk teknis yang didapat dari kementerian pertanian.

\section{Kendala dalam Penyebarluasan Inovasi Sistem Tanam Jajar Legowo}

Berdasarkan pendapat penyuluh di Kecamatan Tumijajar, masih banyak petani yang belum memahami arti dari penerapan Sistem Tanam Jajar Legowo, dan masih banyak petani yang salah mengartikan penggunaan jarak tanam tersebut. Contohnya adalah jarak tanam yang biasanya hanya menggunakan $25 \mathrm{~cm}$ pada sistem Teghel, namun pada Sistem Tanam Jajar Legowo menggunakan 50 $\mathrm{cm}$, petani beranggapan jarak yang terlalu longgar tersebut dapat ditambah tanaman, agar tanaman lebih banyak dan hasil panen juga lebih banyak.

Anggapan petani tentang menambah jumlah tanaman akan menambah jumlah produksi adalah suatu yang keliru, seharusnya jarak tanam yang longgar tersebut digunakan untuk optimalisasi pencahayaan pada proses fotosintesis. Menurut penyuluh, mereka sudah mengingatkan hal tersebut namun petani masih takut menggunakan jarak yang benar karena takut adanya kegagalan dan kerugian dari usahatani tersebut.

Hal lain yang menjadi kendala penyuluh adalah biaya Sistem Tanam Jajar Legowo yang tergolong lebih mahal dari pada sistem tanam sebelumnya. Petani menjadi ragu untuk menerapkan inovasi ini karena takut biaya yang dikeluarkan tidak sebanding dengan pendapatan yang didapat saat panen.

Menurut penyuluh, tugas penyuluh adalah merubah perilaku petani agar menjadi lebih baik, namun setiap keputusan yang diambil oleh petani merupakan hak petani tersebut. Penyuluh tidak dapat memaksa petani untuk menerapkan Sistem Tanam Jajar Legowo. Penyuluh hanya menyarankan penggunaan 


\section{KOMUNIKASI DALAM PENERAPAN SISTEM JAJAR LEGOWO DI DESA MURNI JAYA \\ KECAMATAN TUMIJAJAR KABUPATEN TULANG BAWANG BARAT \\ Erika Dwi Alviana, Tri Pujiana, Dwi Arianti, Helvi Yanfika}

sistem inovasi tersebut karena memiliki keunggulan yang menguntungkan.

Namun, kesalahan penerimaan pesan oleh petani yang mengakibatkan petani enggan menerapkan Sistem Tanam Jajar Legowo perlu diluruskan kembali agar petani paham dan berminat menggunakan Sistem Tanam Jajar Legowo. Upayaupaya pengontrolan dan evaluasi oleh penyuluh setiap selesai musim tanam harus dilakukan agar penyuluh dapat mengetahui apa yang harus diperbaiki dalam pemberian informasi tersebut. Sehingga tujuan dari penerapan inovasi dapat tercapai.

\section{KESIMPULAN DAN SARAN}

Komunikasi yang dilakukan penyuluh sudah cukup baik, hal ini karena penyuluh melakukan pertemuan dengan anggota kelompok tani sebulan sekali, melakukan anjang sana dan anjang karya. Sedangkan petani yang belum mau menerapkan Sistem Tanam Jajar Legowo disebabkan oleh sifat inovasi yang rumit dan pengeluaran biaya untuk menerapkan inovasi lebih besar daripada menggunakan sistem tanam sebelumnya, sehingga masih ada keraguan petani untuk menerapkan inovasi tersebut.

Saran yang dapat diberikan dari penelitian ini adalah perlu adanya perbaikan pada persepsi petani terhadap Sistem Tanam Jajar Legowo agar mereka tidak memiliki ketakutan tersendiri dalam menerapkan inovasi tersebut. Penyuluh perlu meningkatkan intensitas pendampingan kepada petani. Penyuluh juga perlu melakukan pengontrolan dan evaluasi terhadap usahatani padi yang dilakukan oleh petani padi di Murni Jaya.

Komunikasi antara penyuluh dengan petani juga perlu ditingkatkan lagi agar petani lebih percaya terhadap inovasi yang dibawa oleh penyuluh. Inovasi yang dibawa oleh penyuluh sebaik apapun jika petani masih ragu-ragu dalam menerapkannya maka tidak akan berdampak pada perbaikan sistem usahatani. Perlu juga dilakukan evaluasi penyuluhan setiap selesai musim tanam untuk memperbaiki sistem komunikasi antara penyuluh dengan petani.

\section{DAFTAR PUSTAKA}

Abdulrachman, A., dan Jamal, E. 2007. Menjadikan Prima Tani sebagai Ujung Tombak Peningkatan Pendapatan Masyarakat Pedesaan. Lokakarya Nasional. Badan Penelitian dan Pengembangan Pertanian Bogor: Departemen Pertanian.

Abdulracman, et al. 2013. Sistem Tanam Legowo. Badan Penelitian dan Pengembangan Pertanian. Jakarta: Kementerian Pertanian.

Alviana, ED. Gultom, DT., Aviati, Y. 2018. Respon Petani terhadap Sistem Tanam Jajar Legowo di Kecamatan Tumijajar Kabupaten Tulang Bawang Barat. JIIA Agribisnis Unila 6(3): 305-312. 
Bulog. 2016. Ketahanan Pangan. http://www.bulog.co.id/ketahananpa ngan.php. Diakses 5 Desember 2016.

Departemen Pertanian. 2009. Deskripsi Varietas Padi. Balai Besar Penelitian Tanaman Padi. Badan Penelitian dan Pengembangan Pertanian. Jakarta: Departemen Pertanian.

Ekasari, et al. 2015. Konflik Komunikasi dalam Penyuluhan Pertanian di Kabupaten Maros Provinsi Sulawesi Selatan. Jurnal Ilmu Komunikasi, 12(1): 85-97.

Firmansyah, AS. 2015. Fungsi Komunikasi Penyuluh dalam Meningkatkan Hasil Panen Padi pada Petani Sawah Kecamatan Bungaraya Kabupaten Siak Sri Indrapura. Jurnal JOM, 2(2): 1-15.

Ikhwani, Pratiwi, Paturrohman, dan Makarim. 2013. Peningkatan Produktivitas Padi Melalui Penerapan Jarak Tanam Jajar Legowo. Jurnal Iptek Tanaman Pangan, 8(2): 72-79.

Laila, Hajrah., Saleh, Ali S., dan Saadah. 2012. Adopsi Petani Padi Sawah terhadap Sistem Tanam Jajar Legowo 2:1 di Kecamatan
Polongbangkeng Utara, Kabupaten Takalar. J. Sains \& Teknologi. Vol.12No.3: 255 -264 ISSN 14114674.

Nugrahani, F. 2014. Metode Penelitian Kualitatif. Cakra Books. Solo.

Pratama, LD. 2016. Komunikasi Penyuluhan Badan Koordinasi Penyuluhan Provinsi Riau dalam Upaya Meningkatkan Produksi Pertanian di Kecamatan Sentajo Raya Kabupaten Kuantan Singingi. Jurnal JOM FISIP, 3(2): 1-16.

Purwanto, S. 2008. Implementasi Kebijakan Untuk Pencapaian P2BN. Pros. Seminar Apresiasi Hasil Penelitian Padi Menunjang P2BN. Pengendalian Tanaman Padi. Jakarta. Badan Penelitian dan Pengembangan Tanaman Pangan.

Sembiring H. 2001. Komoditas Unggulan Pertanian Provinsi Sumatera Utara. Badan Pengkajian Teknologi Pertanian. Sumatera Utara.

Suriaperrnana, S., I. Syamsia, P. Wardana, Z. Arifin, dan A.M. Fag. 1994. Minapadi: Usaha Tani Berwawasan Lingkungan Meningkatkau Pendapatan. Bogor: Pusat Penelitian dan Pengembangan Tanarnan Pangan. 